\title{
Remembering the Chaos - But Life Went on and the Wound Healed. A Four Year Follow Up with Parents having had a Baby with Infantile Colic
}

\author{
Kajsa Landgren ${ }^{*}$, Anita Lundqvist and Inger Hallström
}

Department of Health Science, Faculty of Medicine, Lund University, P.O. Box 157, SE-221 00 Lund, Sweden

\begin{abstract}
Objective: To elucidate parent's experience of having had a baby with colic four years previously and of how the colic and care influenced the family in a long-term perspective.

Methodology and Participants: A qualitative inductive follow-up study with 13 individual and one focus group interview including four parents. Altogether ten mothers and seven fathers representing 12 families, who had been interviewed when they were in the midst of the colicky period four years ago, were in the present study interviewed between December 2010 and May 2011. Parents' narratives were analysed using content analysis.

Results: Parent's memories of the exhausting colic period were vivid, but when the colic had healed the family relationships also healed. Although it had taken longer time for some parents to attach to their child they now experienced a close relationship with their four year old child and felt confident in their role as parent. The colic scream was still unbearable and evoked negative feelings in the parents. Parents had decreased confidence in Child Health services and made suggestions for improvements in the health care approach. Most of all they wished for an effective treatment of infantile colic.

Conclusion: The family relationships were healed and the colic left only few residual symptoms but parents still had decreased confidence in the Child Health Center. Consequently, there is a need to raise awareness to parents' situation when having a child with infantile colic.
\end{abstract}

Keywords: Baby, content analysis, crying, infantile colic, interviews, long term effects, parents' experiences.

\section{INTRODUCTION}

Infantile colic, which starts within the first few weeks after birth and is defined as "crying or fussing more than three hours/day more than three days/week", strikes about $10 \%$ of newborn babies in Western countries [1]. By definition, infants with colic have excessive and inconsolable crying. In addition, they may have a more distressed and intense cry that is more draining for parents than normal crying [2]. Retrospectively, mothers who have had a baby with colic experienced a variety of thoughts and emotions such as anger, guilt, self-doubt, anxiety, frustration, fear of losing control, hopelessness, fatigue, and disappointment [35]. The studies involving fathers found similar experiences relating to both parents [6-9]. When a baby cries constantly in spite of the parents' attempts at consolation, the balance within the family is disturbed as all of the members of a family are mutually dependent in a complex system [10]. Colic disturbs mother-child $[4,5]$, and father-child relationships $[8,11]$, creates chaos and disrupts family life $[3,9]$. In a previous study, parents were interviewed in the midst of the colicky period [9], showing that the colic overshadowed everything in the families' lives. Both mothers and fathers felt powerless and frustrated, and searched desperately and creatively for treatments to soothe their babie's crying. Parents became very frustrated when

*Address correspondence to this author at the Faculty of Medicine, Department of Health Science, Lund University, Box 157, SE-221 00 Lund, Sweden; Tel: +46739321746; Fax +4642148344;

E-mail: Kajsa.Landgren@med.lu.se they found that no intervention seemed to help. Parents experienced a lack of understanding about their life situation and a lack of support from healthcare professionals [9].

The prognosis for colic is good: $85 \%$ of infants' with colic have remitted when they are 3 months [12]. Nonetheless, besides the baby's presumed suffering, the early interaction and establishment of the essential relationship might be disturbed [6]. Furthermore, infants with persistent crying are more likely to be exposed to physical violence [13]. Having a child with infantile colic is a common reason for parents to ask for advice at a Child Health Centre (CHC). Guiding these parents is a demanding task for nurses [6], but it also provides them with an opportunity to connect with the family system [14]. This connection, in turn, allows nurses to give encouraging and systematic guidance and to help increase parents' sense of self-efficacy [15].

\section{Treatments}

Several hypotheses for the origin of infantile colic have been suggested but there is no consensus of the pathology. There is no known safe and effective cure for infantile colic, but several treatments are available. Symptoms are relieved in $5-20 \%$ of infants with colic after the systematic exclusion of cow's milk protein for five days [16]. Among medications simethicone is the one most commonly used in Sweden. Simethicone is sold over the counter and often recommended by nurses and doctors at $\mathrm{CHC}$, although it has no greater effect on colic than placebo [17]. Dicyclominechlorid has a beneficial effect but also causes severe side effects [17] and 
has been withdrawn in Sweden since 2010. Lactobacillus reuteri is a popular treatment and has shown promising effects but a recent systematic review found no evidence [18] for the effectiveness of probiotic supplements. Acupuncture has been proven to reduce crying and fussing in two randomized trials $[19,20]$ and to soothe gastrointestinal symptoms in one case study with $>900$ infants [21]. Counselling parents has been reported to reduce the infants' crying. Specific instructions about modification of the parent/infant interaction have shown good results $[22,23]$ but, in another study, did not prove to reduce the crying more than assessment and reassurance alone [24].

\section{Long Term Effects of Colic}

Although colic heals spontaneously, it might disturb family relationships and delay attachment [11]. Some studies reporting on the long-term effects of colic on family relationships show that colic may affect interaction between the infant and the parent for a long time after the colic is over [25-28]. Other researchers suggest that maternal behavior may become disturbed when colic is at its peak but returns to normal once the colic has disappeared [29]. Stifter and Bono [30] found that the majority of babies with colic develop secure attachments, but if maternal self-efficacy is low, attachment may be affected. No lasting effects to maternal health were found in a trial with 547 dyads [12].

However, few trials have studied how parents recall the colic period years after it has disappeared. There is also a lack of knowledge about how parents experienced the treatment from professionals and the effect of the care. The aim of this study was to elucidate parents' experiences of having had a baby with colic four years previously and of how the colic and the treatment influenced the family in a long term perspective.

\section{MATERIALS AND METHODOLOGY}

An inductive qualitative descriptive study [31] was performed with parents who had had a baby with colic four years earlier and who had been interviewed about their experiences of having a baby with colic when they were in the midst of the colicky period (the results are published in [9]). To obtain a deeper understanding and understand different perspectives the study includes both individual interviews and a focus group interview where we could study how group members responded to others comments, memories and ideas.

\section{Participants}

Before the first interview, conducted four years ago, parents used a diary to verify that the babies fulfilled the diagnostic criteria: an otherwise healthy infant who the week before the first interview cried for more than three hours per day, more than three days. The babies took part of the ordinary programme at the $\mathrm{CHC}$, which included a visit every week or every second week. In addition to this programme, all parents chose to let their baby try acupuncture, which was available at a private acupuncture clinic.

All of the 23 parents taking part in the previous study [9] were invited to participate in this follow up study. One father declined to participate in the present study due to a lack of time, and one could not be found. One mother who lived far away and one father who had moved abroad agreed to take part, but interviews could not be arranged for practical reasons. One couple scheduled for the focus group interview did not turn up. Consequently, 17 parents (10 mothers and 7 fathers, in the results presented as M1-10 and F1-7) representing 12 families were interviewed. Background variables for the interviewed parents are presented in Table 1. Individual interviews were conducted with five fathers and eight mothers, representing nine families. Four parents (two mothers and two fathers representing three families) took part in the focus group interview (FG).

Table 1. Background Variables of the Participants

\begin{tabular}{|l|l|l|}
\hline & \multicolumn{1}{|c|}{ Mothers } & Fathers \\
\hline \hline $\mathrm{n}$ & 10 & 7 \\
\hline Age, min - max (mean) & $26-44(35)$ & $28-56(39)$ \\
\hline Married/cohabiting & 10 & 7 \\
\hline University degree & 3 & 2 \\
\hline Immigrant n (mean years in Sweden) & $1(6)$ & 0 \\
\hline Having only one child & 2 & 2 \\
\hline Number of children & $1-4$ & $1-4$ \\
\hline
\end{tabular}

\section{Data Collection}

Interviews were conducted between December 2010 and May 2011. Parents who consented to participate in individual interviews were interviewed in the family's home, if they so wished. Ten interviews were conducted by two external interviewers (paediatric nurses) and three by the second author (AL). The focus-group interview was conducted to obtain a deeper understanding of parents' experience and understand different perspectives by studying how group members responded to others comments and ideas. It took place in a room at a conference centre in the nearest town by the second and third authors (AL, IH).

Before all interviews, a presentation and an informal introduction were arranged to create a relaxed atmosphere and to facilitate talking about emotions and experiences [32]. To encourage parents' narration about their experiences, the interviews started with an open question: "Please tell us about your spontaneous memories of having a baby with colic four years ago," followed by follow-up questions if necessary. The interview areas included: spontaneous recollections from the colic period, the colic's influence on family relationships both four years previously and at the time of the interview, impact of the treatment on the family and the support the family received as well as thoughts about future treatment and care. The individual interviews lasted from 30-60 minutes and the focus-group interview 95 minutes. Interviews were tape-recorded and transcribed verbatim. The first ten interviews were transcribed by the interviewers. The remaining interviews were transcribed by the first author $(\mathrm{KL})$.

\section{Ethical Considerations}

The study was carried out in accordance with the Declaration of Helsinki [33]. At the first interview four years 
ago, parents were informed that follow-up interviews were planned. At the second interview, they gave written, informed consent and were informed about the guaranteed confidentiality and the right to discontinue the interviews at any time. All of the participants agreed to have the interviews recorded. Ethical approval was obtained from the University's Research Ethics Committee (Dnr 583/2005).

\section{Data Analysis}

The narratives were analysed with content analysis [34]. First the interviews were listened to and read through several times to obtain a sense of the whole. Then the text was divided into meaning units, i.e. a constellation of words that relate to the same central meaning [34] which were condensed. The next step was to abstract the text into codes. The codes were compared based on differences and similarities and sorted into subcategories and categories. The tentative categories lead to a process to find the underlying meaning including discussion and reflection among all three authors until consensus was reached and the underlying meaning was formulated into themes and sub-themes. The interviews were read again to confirm that all text that was relevant for the purpose was included. Finally an overall theme was formulated, i.e a thread of the underlying meaning of all themes and sub-themes.

In qualitative studies the preunderstanding of the authors is used as a guiding tool in the interpretative process. In order not to influence the interpretation in a biased way we discussed and reflected upon our pre-understanding throughout the process [35]. The first author had met babies with infantile colic and their parents, initially as a nurse at a paediatric emergency unit and for eleven years at an acupuncture clinic. The second and third authors had extensive experience of work and research with children and parents. The first and the third author conducted the previous study [9].

\section{RESULTS}

The overall theme was formulated as "Remembering the chaos but life went on and the wound healed". Themes and sub-themes are shown in Table 2.

\section{Remembering the Chaos but Life went on and the Wound Healed}

The interviews revealed how parents still remembered the colicky period and how the experience of the colic had influenced the family. The analysis revealed a process where the chaotic colicky period faded away and the wound healed without leaving any deep traces in the long run.

It was a terrific relief! It was like we became a whole family instead of a tired and quarrelsome couple. While it lasted we could not even clean the house, or wash the dishes, we didn't even manage to organize a walk with her in the pram. Finally, peace entered the house and then we had the energy to do everything. (F1)

\section{Parental Struggle and Tiredness Turned into Relief with Only a Few Residual Symptoms}

Parents remembered how they had experienced losing control during the colicky period. Everyday life had turned into emotional and practical chaos. Parenting became a matter of struggling to fulfill the family's basic needs. Parents could recall, very vividly, a variety of overwhelming emotions, such as anxiety, frustration, compassion, guilt, shame, and a sense of failure.

\section{I thought that he was dying or something. (M8) \\ There were moments when, both me and my husband... when she was apoplectic and how- ling so much that I almost got this thought, 'now I'll take a pillow and put over her face just until she quietens down, until the scream- ing stops'. (M1)}

The haze of overwhelming exhaustion cleared up. Four years later, the colicky period was still considered to be one of the worst times in life, but in spite of the intensity of the experience, the parents felt that the colic had not seriously influenced the family in the long run. When colic healed, life returned, the wound healed and the memory faded. With four years of perspective, parents noted that it was extremely difficult while it lasted, but that it was still a relatively short time in a life span.

You were ready to throw yourself in front of a train or something. Because it was completely horrible. It's hard to imagine that now when it's over, but it really was like that. (M7)

\section{Isolation Ended Once Social Life Resumed}

During the colic period parents could very rarely leave the house or talk on the phone, friends stopped coming to

Table 2. Overall Theme, Themes and Sub-Themes

\begin{tabular}{|l|l|}
\hline \multicolumn{1}{|c|}{ Remembering the Chaos... } & But Life went on and the Wound Healed \\
\hline \hline $\begin{array}{l}\text { Parental struggle and tiredness... } \\
\text { Isolation... } \\
\text { The colic scream was unbearable... }\end{array}$ & $\begin{array}{c}\text { turned to relief with only a few residual symptoms } \\
\text { ended once social life resumed } \\
\text { and still evokes negative feelings }\end{array}$ \\
\hline $\begin{array}{l}\text { Relationships were strained... } \\
\text { Distance and closeness to the suffering baby... } \\
\text { Feelings of inadequacy... }\end{array}$ & $\begin{array}{c}\text { but healed } \\
\text { but closeness to the four year old child } \\
\text { turned into feelings of confidence in the parental role }\end{array}$ \\
\hline $\begin{array}{l}\text { Not getting the support needed... } \\
\text { Not being understood... }\end{array}$ & $\begin{array}{l}\text { resulted in low confidence in Child Health services and a call for changes } \\
\text { was still considered to have been the worst part } \\
\text { and the need for treatment remains }\end{array}$ \\
\hline
\end{tabular}


visit as well and it was an ordeal to go out with a baby who screamed all the time. Isolation in the home was the option available.

I went to a parenting class, and all the other mothers massaged their baby's tummy. But my baby screamed the whole time, so I couldn't participate. And everyone was singing together, but I had to run out of the room, because they said the screaming was contagious.... I tried to go there two or three times, but every time was the same. (M8)

It was a huge relief when the colic passed, and parents could bring the child with them or invite friends to their home again. Parents' social lives became normalized.

Those who have not had a colicky baby can't understand. You can't explain a delivery, and you can't explain how it is to have colic. (M2)

The colic had passed without leaving any long-term effects on the child, or was it the case that the baby still had feeding or stomach problems, were particularly rough and rowdy, less sensitive to pain and the parents linked the now four year old child's temper tantrums to the colic.

It got worse when we tried new food later on.

... He very often got tummy aches. (FG, M10)

The colic had passed without long-term effects on most parents but one of the fathers who lost 12 kilograms had a maintaining weight loss and one mother still has pain in her knees after months of jumping up and down with the baby in her arms. In eight of the twelve families the child who had colic four years previously had got a younger sibling.

It took five years before we even thought of having another child. Our family would not have survived if we had had another colicky baby. (F5)

While it lasted, the colic distorted the parent's preconceptions regarding life as a parent. The first year did not give as many positive memories as the parents had wished. They had not been able to cuddle the baby, and they were always happy when the baby slept. Four years later, they still envy other parents whose contented babies just sleep and eat, as well as the bond they believe that other mothers have with their new-born babies.

Well, the golden period with a new-born baby - we never had that. We did not! We knew it was super fantastic that we finally got a baby, we wanted it as much as one possibly could. But there is nothing glamorous about the memory of that time, not at all. (FG: F6)

\section{The Colicky Scream was Unbearable and Still Evokes Negative Feelings}

The colicky scream had a special tone and could not be ignored. Colicky crying was experienced as deafening, traumatizing, and extremely draining. The scream inflicted physical pain from hearing it.

It was like, when she was crying, your ears hurt, even if you were in the basement and the baby was upstairs. And, that's not normal. The

crying could penetrate four walls. (M7)

Parents still feared colic and had a hyper-sensitivity to children's crying. Even now, when their own child cried, the memory of the baby's heartbreaking crying night and day was evoked, and parents could still experience physical sensations from hearing other baby's cry.

When we started to suspect that my second daughter also had colic, I panicked. I thought 'Shit, that cry was a colicky cry!' I froze. ...I handed her over to my husband and said 'You take her. I don't want her.' ... I just cried and cried, thinking, 'Not another colicky child. I can't take another one.", (FG: M10)

Parents' experiences had given them a new understanding and increased responsiveness towards other parents with colicky babies. They were willing to support them and were proud that they now can reassure them by telling them they understand their situation and that the colic will pass.

You can hear it now and then, for example, at the [shopping mall], and you know... (takes a deep breath) ...'THAT was not an ordinary cry!'... I want to help. Even if I don't know them, I approach them and give my phone number and tell them "Just call me if you need to sleep an hour." (M7)

\section{Relationships were Strained but Healed}

Relationships within the whole family were strained during the colicky period due to stress, anxiety and tiredness but healed when the colic was over. The feeling of togetherness that the family had longed for eventually came, and parents and siblings were able to fully embrace the baby. It just took a bit longer.

In our case, we had a full family, so my wife took care of the colicky infant and I handled the rest of the children and everything else. The family was divided into two parts and it definitely affected the relationship between me and my wife as we had to over lap... But no, it left no traces in the long run (laughs)! Everyday life and the family just have to go on. (F4) Distance and Closeness to the Suffering Baby and
Closeness to the Four Year Old Child

It had been difficult for some parents to become attached to the colicky baby, and for some parents it had been difficult to feel real happiness with the child until it was over a year old, due to the very limited response from the baby and to being so worn out. For some it took several months after the crying had stopped before they even felt like mothers or fathers. Four years later, all parents had developed a good relationship to the child and sometimes had even formed a closer bond to the formerly colicky baby. While the colic lasted, they had not wanted to put down the screaming child and they had kept the baby physically close to themselves at all times. These children had received plenty of attention, and parents were still more emotionally 
tied to the child. They had pitied the baby so much and had given it extra love and attention.

But every little peep or cry made me put her down or give her to my husband. I felt like I didn't want her. That she wasn't mine. She shouldn't scream like that. It was really: "I don't want to hear your crying anymore, let someone else take you." ... I often think back and realize that I wasn't a mum those months. I lost months of her life and that feels really hard... But now when she is four she is my girl! (M6)

You reject the child. Because you do not have the strength to keep it close. But today, our relation is great, yes, it is very, very, good. She is so spoiled, you can't imagine..." (M2)

In some way, it made me stronger, and made my relationship with my son stronger (pause). Actually (pause). Because I felt that he had no one else but me. 'If I can't manage, no one can.' So I had to cope. (FG: M10)

\section{Feelings of Inadequacy Turned into Feelings of Confidence in the Parental Role}

During the colicky period parents tried hard to get the family to function but had a constant feeling of inadequacy. They felt that others thought that they were bad parents and they worried night and day, as they did not understand why the baby was crying or how to stop it. Four years later, they had experienced the healing of the colic and seen that they could endure, which strengthened their self-esteem. They were now more confident as parents.

When our next child also got colic, we went for acupuncture directly, as it worked so well for the first child. We didn't try anything else. Acupuncture was the only alternative, actually. (F2)

Colic had drained not only the baby/parent-relationship but also other intra-family relationships as well as the parents' romantic relationship. While the colic lasted, parents were more like co-workers than couples, and they saw themselves as double losers: first, for having to stay apart during the screaming attacks so that not everyone had to suffer; second, for continuing to staying apart, so that one parent at a time could recover. Siblings did not get the attention they needed, and their schoolwork and sleep were disrupted. Families with many children or twins had even more difficulties satisfying everyone's needs.

And I remember, when she cried so damn much we went into the closet, where we had placed a chair among the tons of clothes. Because the clothes muffled the sound! All the clothing sucked up so much noise that you could sit and try to calm her down there. And it didn't echo inside your head as much. This way the other person who was outside could get some rest. (FG, F7) (The others laugh) ... This could be a tip for parents with colicky babies, "Sit in the closet!" (FG, M9)
When the colic declined, relationships between parents could become normalized. Fighting the colic together had even strengthened the parents' relationship. They now knew how capable they were, and they were proud that they had endured that difficult period, though they were surprised at their fast recovery.

Maybe we should show how proud and happy we are that we made it and say, 'We made it!' (FG, F6) (all talking at the same time) 'We have had a colicky baby!' It is a qualification! (M9) You can put that in your CV'!' Have had a colicky baby!"(F7)(all laugh). You could get a certificate when it's over!(F6)

In two families, the parents had divorced.

I think many people have a child in an effort to save a relationship. But, if the child gets colic, you split up anyway. That's my experience. I'm divorced now, not only because of the colic, but the colic didn't make it any easier. (M2)

Not Receiving the Support Needed Resulted in a Call for Changes and a Low Confidence in Child Health Services

Parents strongly suggested that professionals learn more about colic. For example, parents were irritated when they had made efforts to exclude cow's milk protein for several weeks without any effect, and later learned that five days is sufficient for determining whether milk is causing the colicky symptoms. And, parents who were informed that colic ends after three months and had relied on this felt despair and hopelessness when it did not correspond with their reality.

$$
\begin{aligned}
& \text { "The nurses are educated, aren't they?" (FG, } \\
& \text { M10) }
\end{aligned}
$$

Parents were desperate and looked for solutions both at the $\mathrm{CHC}$ and outside of the public health system and felt frustration and disappointment when all of their efforts yielded no results, or only helped temporarily.

... the drops [dicykloverinchloride] that they first didn't want to prescribe, due to the strong side effects ... She went incredibly limp and lethargic and tired when we tried them, and she screamed anyway. (M4)

Four years later parents were still critical towards the treatment and had no confidence left in CHC. This was reflected in that they did not visit the $\mathrm{CHC}$ at all any-more, or only brought their children there for weight control and vaccinations but thought it was no idea to ask for advice as they did not trust the advice they got from the CHC any longer. Today the parents have more demands on health care.

No, I would not consider turning to the CHC if I had a new baby who had problems (pause). No, I would really not (pause). No, I don't think very highly of CHC. No. (F5)

Among this disappointment and frustration regarding the professionals there were also some parents who experienced trust in the nurses at the CHC. They were loyal to the nurse, appreciated her and her listening and they considered her to 
be kind and supportive, and good in handling other issues than the colic.

Lack of sleep resulted in desperation. Some got help from their own parents periodically and were sure that they would not have managed without it. Those who could not receive outside help or even help from their partner felt very lonely. Others did not want to expose anyone else to the extremely annoying scream. They also thought it was hard to hear the baby crying in someone else's arms.

Probably we didn't ask for help. No one else would like to have her while she was crying when not even I wanted to have her. (M6)

\section{Not Being Understood was Still Considered to having been the Worst Part}

The biggest disappointment was that they had not been believed and that they did not get reassurance and confirmation. It was frustrating when the professionals or friends and family questioned the existence of colic or belittled the symptoms. There was great disappointment when they received advice that they had already tried in vain from professionals, friends, relatives, magazines and the internet. Likewise it was disappointing when others believed that there was a quick fix for colic, and when absolutely nobody understood their situation or believed in their story.

Even my mom ... she herself has seven children but had never encountered colic. So she thought it was me being a bit impatient, that I was too young, that maybe it wasn't the right time to start a family. (M8)

The nurse at the CHC trivialized parents' experiences of the colicky symptoms and did not take the parents' situation seriously. After four years the parents still experienced how they felt like failures because no one understood. When the nurses belittled the situation and said "all children cry" and "this is what it is like to have children" parents thought that the fault was with them, that they were weaker than other parents.

The nurse said it was normal for babies to cry. She said that colic cannot start as early as the fifth day. But my child did have colic that early, so that was our reality ... When I found out that [simethicone] was a medication with evidence of NOT helping colic, I wanted to go back to the clinic and tell them that. (MI)

\section{Almost Nothing Helped and the Need for Treatment Remains}

The desire was to get a clear diagnosis and a prognosis, a reassurance that colic would eventually pass without any serious side effects. Relief arrived when they were finally reassured that the baby did indeed have colic.

It would have been supportive for us to get the message early: "Sorry, your baby has colic. It's gonna be tough." So that it was made clear ... (FG, F6) Yes, the CHC must be clearer about "this is a colicky baby"... And with "It's really bad now, but it will pass, though it will take time. "(F7)
The professionals did not realize how much the babies cried and the parents recommended professionals to use a diary to measure the amount of crying and fussing so that it would become obvious that the baby cried more than what was normal. When one family begun to use a diary, it was shown that their baby cried 18 hours/day.

The diary made it undeniable that it was bloody awful. And that it was OK for us to be tired. ... It was not us being cuckoo. This was the reality, she was crying this much.( M7)

When parents found out that acupuncture helped their children, they were surprised that $\mathrm{CHC}$ had not recommended it. Several parents considered the acupuncture treatment to have had an effect on the symptoms and it was perceived as mild, simple, fast, and fast-acting. These parents were thoroughly relieved that something finally worked.

We had tried everything else ... I didn't believe in acupuncture any more than I believed in Father Christmas, but acupuncture worked very well. If only $\mathrm{CHC}$ had informed us earlier! We got a new baby after three treatments! (F1)

Parents felt like failures and needed comforting and affirmation that they were good enough as parents. They also needed to be reassured that the colic was not their fault.

A nurse gave me a hug. And I just thought: "Somebody's hugging me! Somebody's hugging ME!' She said: 'You can do this! You will make it there! It's hard now, and he cries a lot now, but you can handle this!' And I said: 'Yes I can, now that you hugged me, I feel strong again! Thank you!' (laughs). (FG, M10)

A short hospitalization was a saving grace for some families and seen as an acknowledgement of the situation. Only then did people around them seem to understand how serious it was.

We told the nurse that we could not stand it any longer. We said "we are dying now". (M7)

Psychological counseling was sought for but with some hesitation. On the one hand it would have been difficult to take part in a counseling session with a screaming baby in one's arms but on the other hand it could have lessened their sense of failure. Others definitely did not want to see a psychologist as they meant it was the child who needed help.

I wish I could have seen someone, some kind of a professional counselor ... Someone who was not the CHC (laughter), where I could have said "I hate the CHC!". That would have been seriously great. (M1)

To get help one family advertised for an extra grandmother and eventually hired a nanny. One suggestion from the parents was that financial support should be granted for maid service or for enabling both parents to stay at home or at least work less during the extreme colicky period. 
Because a colicky baby can create an awful lot of chaos in a perfectly normal family. ( $F G$, M10)

To get emotional support parents would have liked to meet other parents with colicky babies but on the other hand they had no energy to attend, let alone organize group meetings. Yet they expressed a need for a support group with someone who really understood the situation.

\section{DISCUSSION OF METHOD}

Qualitative methods and content analyses are well suited to illuminate participants experiences of a certain phenomenon [34]. When 13 individual interviews were conducted and analysed, we invited parents to a focus group interview, attended by four parents, to further explore their experience. Focus groups are an academic research tool that yields qualitative data in a focused discussion and, thereby, provides insight into complicated topics. We use them to understand how people with certain commonalities feel or think about an issue, and when we are trying to understand differences in perspectives. A response from one participant could trigger memories and thoughts in other participants [32]. The discussion and interaction in the group was lively.

\section{Trustworthiness}

To illuminate how colic had influenced the families in a long term perspective, we choose to perform the interviews when the infant period was well over but before school started. By interviewing the same group of parents twice [9], their experience could be followed over the four year period. In the present study, 17 out of 23 parents took part. The parents had various experiences and backgrounds which increased the possibility of shedding light on the research question from a variety of perspectives. Interviews were conducted in a comfortable, permissive, non-threatening environment. The parents showed high levels of motivation to share their experiences and they spoke openly. Interviews were rich in depth as well as in breadth. The majority of the interviews were conducted individually and supplemented by a focus group interview where skilled moderators enabled parents to discuss experiences without having the pressure of reaching consensus [32], further validating the result of the individual interviews. During the interviews, the interviewers' checked their understanding with follow-up questions. To add depth and insight to the interpretation, the findings were discussed at research seminars with paediatric nurses and midwives. Quotes from the interviews are used to verify that the findings were retrieved from the data. In the present study, we asked parents to recall how it had been having an infant with colic four years previously. The reliability of memories is an interesting issue. Women's ability to recall other key events in life, linked with the memory of labour and childbirth have shown that there is substantial agreement between maternal recall and birth records 3-9 years later [36]. The memory of the colic has probably been recalled repeatedly over the years, and as the interviewed parents in this study had been through an earlier interview they might have reflected on the colic more than other parents. Some details might become lost over the years. However, the aim of the present study was not to investigate the accuracy and consistency of long-term memories of the colicky period.

\section{DISCUSSION OF RESULTS AND CLINICAL IMPLICATIONS}

Parents' memories four years after the colicky period are similar to the experiences they had described when they were in the midst of the period [9]. It is striking how vivid, emotional, and detailed the memory of the experience of having a baby with colic is. Parents recall exact details, and some tell their story in the same words as four years earlier. Some weep, some laugh when they recall situations that were especially difficult. However, parts of the memory have faded out, some details have been lost, the wound have healed, and the families have been repaired. What is apparent is that parents have lost their confidence in the $\mathrm{CHC}$, which is an alarming find, and that they had formulated suggestions for changes. Most of all, parents request an effective treatment of colic and the presence of professionals with a sensitive and keen ear to the families with colicky babies and who would pay attention to the suffering of child and the parents.

Parents' experienced that they had needed to be guided through the colic period. They searched actively for information on colic. Apart from recommendations from professionals, friends, relatives and magazines, they used the Internet for searching for information, including chat rooms, and blogs. This means that they got plenty of information and tips of diverse quality. It is a challenge for professionals to keep up with the parents in seeking and evaluating information about colic and to help the parents to sort out the evidence from mere opinions [37]. When the professionals could not heal the child immediately, the parents in the present study wished that they had at least given clear advice and that advice had been followed up. Parents suggest a manual, a week by week structured set of directions, where treatments are systematically tried and evaluated. To allow this systematical guidance, parents want a more frequent contact with the nurse, as suggested by Long \& Johnson [3].

Parents' experience that nobody understood how much the baby was crying. A clear diagnosis, "Your baby has colic", combined with "There is no cure" and "You did not cause the colic" is better than not being believed, also expressed in Levitzky \& Cooper [38]. A diary was used before inclusion in the first interview study [9] to verify that their baby fulfilled the inclusion criteria, and later when their baby was treated at the acupuncture clinic. Parents appreciated the diary as a tool for reaching an understanding for their situation. For professionals, parent's documentation of their child's behavior can help to identify children who actually cry excessively [6, 39]. Therefore diaries allow professionals to discern when to intervene with medical examinations to exclude diseases in order to spare the parents from unnecessary anxiety. The parents had not got, or not understood, information that colic is a common condition that usually, but not always, heals spontaneously by three or four months of age [12]. Examining the baby to exclude the incidence of disease, and repeating the confirmation that the colic will heal spontaneously might assure parents that the baby is healthy. The use of a diary can also detect parents who have normally crying children but feel that they cry more than children do normally. These families merely need reassurance that they are doing a good job, and a discussion about normal crying and parenthood. 
Moreover, the use of a diary can prevent the baby from unnecessary treatments.

In the present study, parents felt exhaustion, guilt and shame when they could not comfort their baby, and when they got an impulse to harm them, also shown in Long \& Johnson [3] and Levitzky \& Cooper [38]. Professionals who are aware of this risk and explore parental frustration by asking probing questions can ascertain that parents close to shaking their babies are identified. Time and capacity to build a trustful relationship with parents are important to detect and help families at risk [40].

A delay in the development of "good" feelings for the baby was experienced and not all the parents were emotionally stable, with high capacity and good networks. The experience of the colicky period is for some influenced by variables like depression or substance abuse. In these respects, they represent the clinical reality [5,6]. Maternal anxiety, depression, and stress during pregnancy and postpartum have been linked to the development of colic and vice versa [25, 41]. Parents also consider their babies' crying to not only be long-lasting but also as particularly aversive, also described by Zeskind \& Barr [2]. Perceptions of the babies' crying can be altered, for example by depression [42]. Ten per cent of pregnant women are depressed [43] and many stop taking anti-depressants during pregnancy. Professionals, who are aware of mothers showing signs of depression, stress, and substance abuse, can screen those who are at risk. If they also identify families with delayed attachment, they can better be able to help parents to endure the period of colic and provide a secure base for their baby.

The perceived isolation during the colicky period, in line with earlier studies $[3,5]$. Parenting groups are important for developing a good parenthood, and if parents with colicky babies feel that they are included and welcome it can break their isolation.

A request for an effective treatment to shorten the period of colic is on the wish list. All parents in the present study tried acupuncture for their babies and several of them had positive experiences. A positive effect is supported by the few articles published on the topic [19-21, 44]. Although acupuncture is a promising treatment for infantile colic most clinicians request stronger evidence before introducing a new treatment and further research is required. As no negative side effects are reported and no other safe and effective treatment is known, acupuncture can be considered as a treatment.

The birth of a child, especially a first child, represents a landmark event in life that results in parents being very vulnerable [45]. Parents in the present study want to give their eagerly awaited child everything. Not being able to comfort the baby challenge their self-esteem as they perceive a loss of competence as parents, like in Megel et al., [5]. Infant crying and parental response is the first language of the new dyadic relationship. Misunderstandings can compromise infant care and parental effectiveness, and undermine the budding relationship [42]. However, parents in the present study experience that having managed a family through the colicky period strengthened their self-esteem. Supportive care may protect parents from a long-lasting negative experience [46]. In the period of infantile colic, the way parents are treated by the professionals may determine their long-term feeling about the experience. Professionals can support parents by helping them remember the baby period with joy and pride and a sense of accomplishment. By focusing on solutions and parents' strengths, and by commending parents and telling them that they are doing a great job, nurses could minimize the risk of parents being stuck in feelings like helplessness and failure. Praising the child also makes parents feel proud. This could change their behavior towards the child, as well as each other [47, 48]. Active listening, compassion, and empathy are nurturing kinds of behavior associated with raising parents' selfefficacy beliefs, thereby influencing their performance [15].

\section{CONCLUSION}

Four years later, parent's memories of the colicky period are still vivid and emotional, but the family relationships have healed and the colic left only a few residual symptoms. Parents have specific needs when having a baby with colic. Professionals in $\mathrm{CHC}$ are advised to identify problems and support the parents and the child. Consequently, there is a need to raise awareness to parent's situation when having a child that is suspected to have infantile colic.

\section{ACKNOWLEDGEMENTS}

The parents who shared their experience. Lena Larsson and Bente Sandberg who conducted the first ten interviews.

\section{CONFLICT OF INTEREST}

\author{
Declared none.
}

\section{REFERENCES}

[1] Canivet C, Jakobsson I, Hagander B. Colicky infants according to maternal reports in telephone interviews and diaries: a large Scandinavian study. J Dev Behav Pediatr 2002; 23(1): 1-8.

[2] Zeskind PS, Barr RG. Acoustic characteristics of naturally occurring cries of infants with "colic". Child Dev1997; 68(3): 394403.

[3] Long T, Johnson M. Living and coping with excessive infantile crying. J Adv Nurs 2001; 34(2): 155-62.

[4] Keefe MR, Froese-Fretz A. Living with an irritable infant: maternal perspectives. MCN Am J Matern Child Nurs 1991; 16(5): 255-9.

[5] Megel ME, Wilson ME, Bravo K, McMahon N, Towne A. Baby lost and found: mothers' experiences of infants who cry persistently. J Pediatr Health Care 2011; 25(3): 144-52.

[6] Helseth S. Hjelp i skrikende stund. Utvikling av en modell for helsesöster-tilnaerming til foreldre og barn når spedbarnet har kolikk.: Oslo Universitet 1999.

[7] Ellett ML, Swenson M. Living with a colicky infant. Gastroenterol Nurs 2005; 28(1): 19-25.

[8] Ellett ML, Appleton MM, Sloan RS. Out of the abyss of colic: a view through the fathers' eyes. MCN Am J Matern Child Nurs 2009; 34(3): 164-71.

[9] Landgren K, Hallstrom I. Parents' experience of living with a baby with infantile colic - a phenomenological hermeneutic study. Scand J Caring Sci 2011; 25 (2): 317-24.

[10] Bateson G. Mind and Nature - a necessary unity. New York: Bantam New Age 1979.

[11] Raiha H, Lehtonen L, Huhtala V, Saleva K, Korvenranta H. Excessively crying infant in the family: mother-infant, father-infant and mother-father interaction. Child Care Health Dev 2002; 28(5): 419-29.

[12] Clifford TJ, Campbell MK, Speechley KN, Gorodzinsky F. Sequelae of infant colic: evidence of transient infant distress and absence of lasting effects on maternal mental health. Arch Pediatr Adolesc Med 2002; 156(12): 1183-8.

[13] Talvik I, Alexander RC, Talvik T. Shaken baby syndrome and a baby's cry. Acta Paediatr 2008; 97(6): 782-5. 
[14] Wright L, Lehey M. Nurses and families. A guide to family assessment and intervention. Philadelphia: F.A. Davis Company 2005.

[15] Trivette C, Dunst C, Hamby D. Influences of Family-Systems Intervention Practices on Parent-Child Interactions and Child Development. Topics Early Child Spec Educ 2010; 3-19.

[16] Iacovou M, Ralston RA, Muir J, Walker KZ, Truby H. Dietary Management of Infantile Colic: a systematic review. Matern Child Health J 2011; Jun 28 [Epub ahead of print].

[17] Lucassen PL, Assendelft WJ, Gubbels JW, van Eijk JT, van Geldrop WJ, Neven AK. Effectiveness of treatments for infantile colic: systematic review. BMJ 1998; 316(7144): 1563-9.

[18] Perry R, Hunt K, Ernst E. Nutritional supplements and other complementary medicines for infantile colic: a systematic review. Pediatrics 2011; 127(4): 720-33.

[19] Reinthal M, Andersson S, Gustafsson M, et al. Effects of minimal acupuncture in children with infantile colic - a prospective, quasirandomised single blind controlled trial. Acupunct Med 2008; 26(3): 171-82.

[20] Landgren K, Kvorning N, Hallstrom I. Acupuncture reduces crying in infants with infantile colic: a randomised, controlled, blind clinical study. Acupunct Med 2010; 28(4): 174-9.

[21] Reinthal M, Lund I, Ullman D, Lundeberg T. Gastrointestinal symptoms of infantile colic and their change after light needling of acupuncture: a case series study of 913 infants. Chin Med 2011; 6: 28 .

[22] Keefe MR, Barbosa GA, Froese-Fretz A, Kotzer AM, Lobo M. An intervention program for families with irritable infants. MCN Am J Matern Child Nurs 2005; 30(4): 230-6.

[23] Dihigo SK. New strategies for the treatment of colic: modifying the parent/infant interaction. J Pediatr Health Care 1998; 12(5): 25662.

[24] Parkin PC, Schwartz CJ, Manuel BA. Randomized controlled trial of three interventions in the management of persistent crying of infancy. Pediatrics 1993; 92(2): 197-201.

[25] Rautava P, Lehtonen L, Helenius H, Sillanpaa M. Infantile colic: child and family three years later. Pediatrics 1995; 96: 43-7.

[26] Lehtonen L, Korhonen T, Korvenranta H. Temperament and sleeping patterns in colicky infants during the first year of life. J Dev Behav Pediatr 1994; 15(6): 416-20.

[27] Ellett M, Schuff E, Davis JB. Parental perceptions of the lasting effects of infant colic. MCN Am J Matern Child Nurs 2005; 30(2): 127-32.

[28] Canivet C, Jakobsson I, Hagander B. Infantile colic. Follow-up at four years of age: still more "emotional". Acta Paediatr 2000; 89(1): 13-7.

[29] Stifter C, Braungart J. Infant colic: a transient condition with no apparent effects. J Appl Dev Psychol 1992; 13: 447-62.

[30] Stifter CA, Bono MA. The effect of infant colic on maternal selfperceptions and mother-infant attachment. Child Care Health Dev1998; 24(5): 339-51.
[31] Sandelowski M. Whatever happened to qualitative description? Res Nurs Health 2000; 23(4): 334-40.

[32] Krueger R, Casey M. Focus groups: a practical guide for applied research. Thousand Oaks, London, New Delhi: Sage Publications Inc 2000.

[33] Association TWM. The World Medical Association. World Medical Association Declaration Of Helsinki: Ethical Principles for Medical Research Involving Human Subjects 2007.

[34] Graneheim UH, Lundman B. Qualitative content analysis in nursing research: concepts, procedures and measures to achieve trustworthiness. Nurse Educ Today 2004; 24(2): 105-12.

[35] Kvale S. Den kvalitativa forskningsintervjun Lund: Studentlitteratur 1997.

[36] Sou SC, Chen WJ, Hsieh WS, Jeng SF. Severe obstetric complications and birth characteristics in preterm or term delivery were accurately recalled by mothers. J Clin Epidemiol 2006; 59(4): 429-35.

[37] Catherine NL, Ko JJ, Barr RG. Getting the word out: advice on crying and colic in popular parenting magazines. $\mathrm{J}$ Dev Behav Pediatr 2008; 29(6): 508-11.

[38] Levitzky S, Cooper R. Infant colic syndrome--maternal fantasies of aggression and infanticide. Clin Pediatr (Phila) 2000; 39(7): 395400 .

[39] Helseth S, Begnum S. A comprehensive definition of infant colic: parents' and nurses' perspectives. J Clin Nurs 2002; 11(5): 672-80.

[40] Wade K, Black A, Ward-Smith P. How mothers respond to their crying infant. J Pediatr Health Care 2005; 19(6): 347-53.

[41] Keefe MR, Lobo ML, Froese-Fretz A, Kotzer AM, Barbosa GA, Dudley WN. Effectiveness of an intervention for colic. Clin Pediatr (Phila) 2006; 45(2): 123-33.

[42] LaGasse LL, Neal AR, Lester BM. Assessment of infant cry: acoustic cry analysis and parental perception. Ment Retard Dev Disabil Res Rev 2005; 11(1): 83-93.

[43] Andersson L, Sundstrom-Poromaa I, Bixo M, Wulff M, Bondestam K, Strom M. Point prevalence of psychiatric disorders during the second trimester of pregnancy: a population-based study. Am J Obstet Gynecol 2003; 189(1): 148-54.

[44] Landgren K, Hallström I. Akupunkturbehandling vid spädbarnskolik - föräldrars upplevelser av barnets beteende före och efter behandling. Vård i Norden 2005;1: 26-31.

[45] Simkin P. Just another day in a woman's life? Part II: Nature and consistency of women's long term memories of their first birth experiences. Birth1992; 19(2): 64-81.

[46] Waldenström U. Why do some women change their opinion about childbirth over time? Birth 2004; 31(2): 102-7.

[47] Limacher LH, Wright L. Commendations: Listening to the silent side of a family intervention. J Fam Nurs 2003; 9: 130-5.

[48] Feeley N, Gottlieb L. Nursing approaches for working with family strengths and resources. J Fam Nurs 2000; 6(1): 9-24.

Received: November 7, 2011

Revised: February 22, 2012

Accepted: February 23, 2012

(C) Landgren et al.; Licensee Bentham Open.

This is an open access article licensed under the terms of the Creative Commons Attribution Non-Commercial License (http://creativecommons.org/licenses/by$\mathrm{nc} / 3.0 /$ ) which permits unrestricted, non-commercial use, distribution and reproduction in any medium, provided the work is properly cited. 